\title{
Large-scale Genomic Testing Facilitates Precision Medicine in Routine Cancer Care
}

\author{
An Expert Interview with Ricardo H Alvarez \\ Breast Cancer Center, Cancer Treatment Centers of America (CTCA), Atlanta, GA, USA
}

DOI: https://doi.org/10.17925/OHR.2019.15.1.25

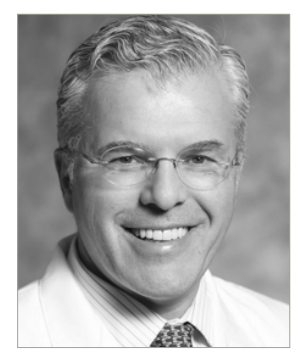

\section{Ricardo H Alvarez}

Ricardo Alvarez, a native of Argentina, is internationally known for his contribution to breast cancer multidisciplinary management, inflammatory breast cancer, and discovery and monitoring of minimal residual disease in solid tumors. As a medical oncologist, he has focused his clinical career, the past two decades, on treating patients with the most difficult cases of breast cancer. Following his training in Argentina, Dr Alvarez moved to Houston to pursue a medical residency in internal medicine at The University of Texas at Houston, and completed a fellowship in hematology and oncology at The University of Texas MD Anderson Cancer Center, Houston, TX. He served for 5 years as an Assistant Professor in the University of Texas MD Anderson Cancer Center Department of Breast Medical Oncology, Division of Cancer Medicine. He also served as Assistant Professor at The Morgan Welch Inflammatory Breast Cancer Research Program. Dr Alvarez has authored more than 50 articles, abstracts and book chapters and is a frequent presenter at international oncology conferences. He has received numerous professional awards for his work in cancer research, including T-32 NIH CA009666 in 2006, Award of Excellence in Cancer Research by Texas Medical Society of Oncology in 2008, and the Susan Papizan Dolan Fellowship in Breast Cancer Research in 2008.

\section{Keywords}

Precision medicine, next-generation genomic sequencing, cancer treatment, advanced cancer, gene abnormalities

Disclosure: Ricardo H Alvarez has nothing to disclose in relation to this article.

Acknowledgment: Medical writing assistance was provided by Katrina Mountfort of Touch Medical Media, and supported by Touch Medical Media.

Review Process: This is an expert interview and, as such, has not undergone the journal's standard peer review process.

Authorship: The named author meets the Internationa Committee of Medical Journal Editors (ICMJE) criteria for authorship of this manuscript, takes responsibility for the integrity of the work as a whole, and has given final approval to the version to be published.

Received: November 1, 2018

Published Online: January 28, 2019

Citation: Oncology \& Hematology Review. 2019;15(1):25-6

Corresponding Author: Ricardo H Alvarez, Cancer Treatment Centers of America - Atlanta, 600 Celebrate Life Parkway, Newnan, GA 30265 USA. E: ricardo.alvarez@ctca-hope.com Twitter @rhalvarez1

Support: No funding was received in the publication of this article.
O ver the last decade, genomics has become an increasingly important part of cancer care. In some tumor types, such as lung cancer and melanoma, genetic profiling for actionable mutations has become standard clinical practice. ${ }^{1,2}$ The development of novel targeted molecular therapies together with the increased availability of next-generation genomic sequencing has led to an interest in genomic profiling in routine cancer care. ${ }^{3-6}$ However, the complexity of nextgeneration sequencing has prevented many laboratories from implementing it on a large scale. Recently, studies have shown that this approach is feasible in large study populations. ${ }^{7-9}$

In an expert interview, conducted at the European Society for Medical Oncology (ESMO) 2018 Congress, which was held in Munich, Germany, from October 19-23, 2018, Ricardo Alvarez discusses the mutational landscape of metastatic cancers discovered from prospective clinical sequencing at a community practice cancer program, and the findings from the data he presented at ESMO 2018. ${ }^{\circ}$

\section{Q. What proportion of cancer patients in your institution are receiving drugs matched to mutations in their tumors?}

Approximately $39 \%$ of all of our patients undergo a next-generation genomic sequencing text. Of these, around one-quarter to one-third are treated with genetic biomarker-directed treatment. This is a substantial proportion considering that this is a new approach of precision medicine.

\section{Q. Could you tell us a little about the data you are presenting from community practices?}

These data were collected over 5 years and comprised a total of approximately 8,000 samples from 7,600 patients with advanced cancer. ${ }^{9}$ DNA alterations were identified in $94 \%$ of tumor samples, and of these, $47 \%$ were considered clinically relevant. The personalized medicine programs helped the physician to assign patients to individual targeted therapy. This is an important study; all patients assigned to molecular targeted therapy responded better and the personalized medicine program helped the physician to identify clinical trials. 


\section{Q. Which tumors are most amenable to this approach?}

The majority of patients amenable to personalized therapy with nextgeneration genomic sequencing are those with breast cancer, lung cancer, colorectal cancer, gynecological cancers and non-primary cancers. For patients with these tumors, we have found actionable mutations in 28 $30 \%$ of cases. These can be treated effectively with targeted therapies and represent some of the most common cancers.

\section{Q. What are the limitations of this approach?}

The first limitation is the cost: not all patients are able to participate in these studies and have access to genomic sequencing. In addition, access to clinical trials is not available for all these mutations, therefore we often treat off-label. Obtaining drugs for off-label treatment is an important barrier.

\section{Q. By how much do you expect the proportion of cancer patients receiving matched treatment to rise in the coming years?}

It is hard to predict but most large institutes in the US have nextgeneration sequencing platforms, which they can offer to selected patients. The increasing frequency of matching treatment over time and the availability of immunotherapy and matching with programmed death ligand 1 (PD-L1) status and tumor mutational burden may further increase this population. It is important to remember that, a few years ago, precision medicine was only used in the research setting and now it is available in routine clinical care, and we are seeing increasing numbers of patients taking part. A lot of studies are showing that this approach is highly selective for increased response rates and progression-free survival.]
1. Chapman PB, Hauschild A, Robert $\mathrm{C}$, et al. Improved survival with vemurafenib in melanoma with BRAF V600E mutation. N Eng/ J Med. 2011;364:2507-16

2. Lindeman NI, Cagle PT, Beasley MB, et al. Molecular testing guideline for selection of lung cancer patients for EGFR and ALK tyrosine kinase inhibitors: guideline from the college of American Pathologists, International Association for the Study of Lung Cancer, and Association for Molecular Pathology. J Mol Diagn 2013:15:415-53.

3. Singh RR, Patel KP, Routbort MJ, et al. Clinical validation of a next-generation sequencing screen for mutational hotspots in 46 cancer-related genes. J Mol Diagn. 2013:15:607-22.

4. Roychowdhury S, Iyer MK, Robinson DR, et al. Personalized oncology through integrative high-throughput sequencing: a pilot study. Sci Trans/ Med. 2011;3:111ra21.

5. Frampton GM, Fichtenholtz A, Otto GA, et al. Development and validation of a clinical cancer genomic profiling test based on massively parallel DNA sequencing. Nat Biotechnol. 2013:31:1023-31.

6. Simen $\mathrm{BB}$, Yin $\mathrm{L}$, Goswami $\mathrm{CP}$, et al. Validation of a nextgeneration-sequencing cancer panel for use in the clinical laboratory. Arch Pathol Lab Med. 2015;139:508-17.
7. Meric-Bernstam F, Brusco L, Shaw K, et al. Feasibility of largescale genomic testing to facilitate enrollment onto genomically matched clinical trials. J Clin Oncol. 2015;33:2753-62.

8. Zehir A, Benayed R, Shah RH, et al. Mutational landscape of metastatic cancer revealed from prospective clinical sequencing of 10,000 patients. Nat Med. 2017;23:703-13.

9. Alvarez RH, Moran A, Meiri E, et al. Mutational landscape of metastatic cancers discovered from prospective clinical sequencing at community practice cancer program. Presented at: European Society for Medical Oncology (ESMO) 2018 Congress, Munich, Germany, October 19-23, 2018. 